\title{
Analisis Kelayakan Finansial Usaha Pembibitan Sapi Potong Di Desa Pucuk Kecamatan Pucuk Kabupaten Lamongan
}

\section{Analysis Feasibility Financial of Beef Cattle Breeding in the Pucuk Village, Pucuk Districts, Lamongan District}

\author{
Ahmad Khoiri ${ }^{1}$, Ir. Nuril Badriyah ${ }^{2}$, Drh. Dyah Wahyuning Aspriati, S.Pt ${ }^{3}$ \\ ${ }^{1}$ Mahasiswa Fakultas Peternakan \\ ${ }^{2}$ Dosen Pembimbing Utama \\ ${ }^{3}$ Dosen Pembimbing Pendamping \\ Program Studi Peternakan \\ Fakultas Peternakan, Universitas Islam Lamongan (UNISLA)
}

\section{RINGKASAN}

Tujuan penelitian adalah untuk mengetahui kelayakan finansial ternak sapi potong di Desa Pucuk, Kecamatan Pucuk, Kabupaten Lamongan. Lokasi penelitian ini dilakukan pada beberapa peternakan di Desa Pucuk, Kecamatan Pucuk, Kabupaten Lamongan. dan waktu pelaksanaan penelitian ini dilaksanakan pada tanggal 23 Juni 2016 sampai tanggal 23 Juli 2016. Materi pada penelitian ini adalah beberapa peternakan di Desa Pucuk, Kecamatan Pucuk, Kabupaten Lamongan, dipilih pada peternakan yang sudah berpengalaman minimal 2 tahun dan peternakan dengan usaha sapi minimal 5 ekor. Populasi dalam penelitian adalah seluruh peternakan sapi potong di Desa Pucuk, Kecamatan Pucuk, Kabupaten Lamongan sebanyak 10 peternak. Dan sampel dari penelitian ini adalah 5 peternakan yang ada di Desa Pucuk, Kecamatan Pucuk, Kabupaten Lamongan. Data yang digunakan dalam penelitian ini adalah berupa data primer dan data skunder, baik yang bersifat kualitatif dan kuantitatif. Proses pengambilan data primer dilaksanakan dengan melakukan pengamatan, wawancara peternak dengan panduan kuisioner yang telah disiapkan. Data skunder diperoleh dari literatur-literatur, arsip dari beberapa pemilik peternakan sapi potong di Kecamatan Pucuk, Kabupaten Lamongan, dan lembaga-lembaga lain yang berhubungan dengan penelitian ini. Analisis data yang digunakan dalam penelitian ini adalah analisis statistik deskriptif yaitu statistik yang digunakan untuk menganalisis data dengan cara mendeskripsikan atau menggambarkan data yang telah terkumpul sebagaimana adanya tanpa bermaksud membuat kesimpulan yang berlaku untuk umum atau generalisasi, dengan menghitung pendapatan dan finansial (BEP, R/C Ratio dan B/C Ratio). Hasil dari penelitian ini adalah kelayakan usaha pembibitan sapi potong di Desa Pucuk, Kecamatan Pucuk, Kabupaten Lamongan layak dari segi pendapatan, penerimaan maupun finansial (BEP dan R/C Ratio), akan tetapi jika dinilai dari sisi Benefit Cost Ratio (B/C) dari 5 sample peternakan hanya ada 1 peternak yang layak dan menguntungkan yaitu peternakan dengan populasi 40 ekor.

Kata kunci : analisis finansial,sapi potong

\section{ABSTRACT}

Purpose analysis is to know Feasibility of beef cattle breeding in the pucuk village, pucuk districts, lamongan district and to know wat is beef cattle businnes can help the lives family farmers in meeting the basic needs of society. Material and studies are some breedears in the pucuk village, pucuk districts, lamongan district, been on some farms that have been experienced for 2 years and a farm with cattle bisiness at least 5 years. The population is all farms in the pucuk village, pucuk districts, lamongan district, as many as 10 farmers. And take samples of 5 farms in the pucuk village, pucuk districts, lamongan district. Data used in this study are primary data and secondary data, both qualitative and kuantitatif. Proses experience changed the primery data conducted by observation, interview guindes farm with a quistionnaire that has been prepared. Secondary data obtained from the literature-litelatur, archives of beef cattle farms in the pucuk village, pucuk districts, lamongan district. The data analysis used in this research of descriptive statistics, namely ststistics used to analyze data in a way to describe or portray the collected data as it is without intending to make conclusions or generalizations apply to the public, by calculating the income and financial (BEP, R/C Ratio dan B/C Ratio). The results of this study is the feasibility Analysis Feasibility of beef cattle breeding in the pucuk village, pucuk districts, lamongan district, decent in terms of revenues, receipts, 
and fiancial (BEP dan R/C Ratio), but if judged from the side Benefit Cost Ratio (B/C) of 5 samples only one viable farms with a population of 40 fish.

\section{PENDAHULUAN}

Untuk memenuhi kebutuhan daging sapi nasional 2016 sebesar 674,69 ribu ton, telah dipotong sekitar 3,9 juta ekor sapi. Prospek usaha sapi potong cukup bagus sejalan dengan meningkatnya penduduk, maka kebutuhan protein hewani akan meningkat. Selain itu, menurunnya import sapi dari Amerika, Australia, India dan lain-lain karena penyakit Antrax, mulut dan kuku serta sapi gila, mendorong usaha sapi potong lokal menjadi trend dan banyak diminati.

Tetapi menurut data statistik di Kabupaten Lamongan Jawa Timur populasi sapi potong setiap tahunnya tidak stabil yaitu pada tahun 2011 mencapai 109.972, pada tahun 2012 mengalami kenaikan 116.96, kemudian pada tahun 2013 mengalami banyak penurunan 96.714, dan pada tahun 2014 sedikit mengalami kenaikan yaitu 99.714 (Disnak jatim 2015).

Kecamatan Pucuk adalah salah satu wilayah di Kabupaten Lamongan dengan luas wilayah Kecamatan Pucuk $43 \mathrm{Km}^{2}$ atau 4.311,98 Ha terbagi dalam 34 Dusun, 66 RW, dan 265 RT. dari luas tersebut sebagian besar untuk sawah, yakni seluas 2.898,59 ha, selebihnya untuk tegalan, waduk, rawa-rawa, pekarangan dan lain-lain (Badan Pusat Statistik).

Kondisi ini tidak memungkinkan masyarakat daerah untuk mengandalkan hasil di sektor pertanian semata. Salah satu usaha yang dilakukan oleh masyarakat untuk memperoleh pendapatan adalah dengan melakukan usaha peternakan.

Pembibitan sapi potong adalah sumber utama sapi bakalan bagi usaha penggemukan sapi potong. Dilihat dari muka sapi, matanya tampah cerah dan bersih, tidak terganggu pernapasannya serta dari hidung tidak keluar lendir. Kalau dilihat dari tubuh sapi, kukunya tidak terasa panas bila diraba, tidak terlihat adanya eksternal parasit pada kulit dan bulunya, tidak terdapat adanya tanda-tanda mencret pada bagian ekor dan dubur, tidak ada tanda-tanda kerusakan kulit dan perontokan bulu. pusarnya bersih dan kering, bila masih lunak dan tidak terbulu menandakan bahwa pedet maupun masih berumur kurang dari dua hari.
Biaya sebagai suatu sumberdaya yang dikorbankan atau dilepaskan untuk mencapai tujuan tertentu. Suatu biaya biasanya diukur dalam unit uang yang harus dikeluarkan dalam rangka mendapatkan barang dan jasa (Horngren Charles et.al,2008 dikutip dalam Tri, Ariani 2015).

Maka dari itu perlu adanya analisis finansial, dengan adanya analisis finansial kemungkinan keuntungan dan kerugian dapat di ketahui.

\section{MATERI DAN METODE}

Materi dan penelitian ini adalah beberapa peternakan di Desa Pucuk, Kecamatan Pucuk, Kabupaten Lamongan, dengan kriteria :

1. Peternakan sudah berpengalaman minimal 2 tahun.

2. Peternak dengan usaha sapi minimal 5 ekor.

\section{METODE PENELITIAN}

Metode yang digunakan dalam penelitian ini adalah survei dan studi kasus, dimana metode survei adalah pengamatan langsung ke lapangan untuk mengetahui objek yang akan diteliti (Arikunto, 2006). Sedangkan studi kasus adalah metode yang menganalisis secara lebih mendalam pada satu daerah tertentu dengan luas areal peternakan terbatas.

\section{VARIABEL YANG DIAMATI}

Data yang digunakan dalam penelitian ini adalah berupa data primer dan data skunder, baik yang bersifat kualitatif dan kuantitatif. Proses pengambilan data primer dilaksanakan dengan melakukan pengamatan, wawancara peternak dengan panduan kuisioner yang telah disiapkan. Sugiyono (2009) mengungkapkan bahwa kuisioner adalah teknik pengumpulan data yang dilakukan dengan cara memberi seperangkat pertanyaan atau pernyataan tertulis kepada responden untuk dijawabnya.

Data skunder diperoleh dari literaturliteratur, arsip dari beberapa pemilik peternakan sapi potong di kecamatan Pucuk, kabupaten Lamongan, dan lembaga-lembaga lain yang berhubungan dengan penelitian ini.

\section{LOKASI DAN WAKTU PENELITIAN}

Lokasi penelitian ini dilakukan pada beberapa peternakan di Desa Pucuk, 
Kecamatan Pucuk, Kabupaten Lamongan. Penelitian dilakukan didaerah tersebut karena daerah tersebut termasuk salah satu sentra peternakan sapi potong di Kabupaten Lamongan. Dan waktu pelaksanaan penelitian ini dilaksanakan pada tanggal 23 Juni 2016 sampai tanggal 23 Juli 2016.

\section{ANALISIS DATA}

Analisis data yang digunakan dalam penelitian ini yaitu analisis statistik deskriptif yaitu statistik yang digunakan untuk menganalisis data dengan cara mendeskripsikan atau menggambarkan data yang telah terkumpul sebagaimana adanya tanpa bermaksud membuat kesimpulan yang berlaku untuk umum atau generalisasi, dengan menghitung pendapatan dan finansial yaitu:

\section{Break Even Point (BEP)}

Analisis BEP adalah suatu cara yang digunakan untuk mengetahui pada volume penjualan dan volume produksi berapakah perusahaan yang bersangkutan tidak menderita keuntungan dan tidak pula memperoleh laba. Menurut Sigit, 1979 dikutip dalam Diatmojo, et, al., 2012, analisis BEP dirumuskan:

$$
\text { BEP }=\frac{\text { Biaya Tetap }}{\text { Biaya Variable Total }} \frac{\text { Total Penjualan }}{\text { Bala }}
$$

Ada tiga kriteria dalam BEP , yaitu:

BEP > 0, maka usaha tersebut layak dan menguntungkan.

$\mathrm{BEP}=0$, maka usahatani tersebut tidak untung dan tidak rugi.

BEP $<0$, maka tidak layak atau merugikan.

2. R/C Ratio (Return Cost Ratio)

Menurut Soekartawi (1995) dikutip dalam

Tri, Ariani, (2015), R/C Ratio (Return

Cost Ratio) merupakan perbandingan antara penerimaan dan biaya, yang secara matematik dapat dinyatakan sebagai berikut:

$$
\mathrm{R} / \mathrm{C}=\mathrm{P}_{\mathrm{Q}} \cdot \mathrm{Q} /(\mathrm{TFC}+\mathrm{TVC})
$$

Ada tiga kriteria dalam $R / C$ ratio, yaitu:

$\mathrm{R} / \mathrm{C}$ rasio $>1$, maka usaha tersebut layak dan menguntungkan.

$\mathrm{R} / \mathrm{C}$ rasio $=1$, maka usahatani tersebut tidak untung dan rugi.

$\mathrm{R} / \mathrm{C}$ rasio < 1, maka tidak layak atau merugikan.

3. B/C Ratio (Benefit Cost Ratio)
Net B/C merupakan perbandingan antara present value dari net benefit yang positif dengan present value dari net benefit yang negatif. Net $\mathrm{B} / \mathrm{C}$ digunakan untuk melihat seberapa besar manfaat bersih yang diterima (Gittinger, 1986 dikutip dalam Tri, Ariani, (2015)). Rumusan yang digunakan adalah:

$$
\text { Net } B / C=\frac{\sum_{t=1}^{n} \frac{B t-C t}{(1+i)^{t}}}{\sum_{t=1}^{n} \frac{C t-B t}{(1+i)^{t}}}
$$

Ada tiga kriteria dalam $R / C$ ratio, yaitu:

$\mathrm{BCR}>1$, maka usaha tersebut layak dan menguntungkan.

$\mathrm{BCR}=1$, maka usahatani tersebut tidak untung dan tidak rugi.

$\mathrm{BCR}<1$, maka tidak layak atau merugikan.

\section{HASIL DAN PEMBAHASAN Analisis Finansial Usaha}

\section{Analisa Break Even Point (BEP)}

Analisa ini menggunakan pendekatan untuk penetuan jumlah barang yang dijual pada harga tertentu untuk menutupi biaya yang ada karena transaksi tersebut.

Adapun break even point yang diperoleh para di Desa Pucuk, Kecamatan Pucuk, Kabupaten Lamongan dapat dilihat pada tabel 10.

Tabel 10. Break event point Usaha Ternak Sapi Potong Desa Pucuk, Kecamatan Pucuk, Kabupaten Lamongan Pada Tahun 2014-2015

\begin{tabular}{clrc}
\hline & & \multicolumn{2}{c}{ BEP (\%) } \\
\cline { 3 - 4 } No. & Peternakan & Tahun & Tahun \\
& & $\mathbf{2 0 1 4}$ & $\mathbf{2 0 1 5}$ \\
\hline 1 & Reny & 0,65 & 0,45 \\
& Afidah & 0,50 & 0,77 \\
2 & Chandra & 0,53 & 0,56 \\
3 & Aang & 0,56 & 1,37 \\
4 & Riyanto & 0,71 & 0,66 \\
5 & Suep &
\end{tabular}

Sumber : Data Primer yang Telah Diolah Pada Tahun 2014-2015.

Pada tabel.10 dari usaha ternak sapi potong di Desa Pucuk, Kecamatan Pucuk, Kabupaten Lamongan. Pada peternakan milik Reny Afidah dapat dilihat BEP produksinya pada tahun 2014 yakni sebesar 0,65 sedangkan pada tahun 2015 yakni 0,45 , peternakan milik 
Chandra dapat dilihat BEP produksinya pada tahun 2014 yakni sebesar 0,50 sedangkan pada tahun 2015 yakni 0,79, peternakan milik Aang dapat dilihat BEP produksinya pada tahun 2014 yakni sebesar 0,53 sedangkan pada tahun 2015 yakni 0,56, peternakan milik Riyanto dapat dilihat BEP produksinya pada tahun 2014 yakni sebesar 0,56 sedangkan pada tahun 2015 yakni 1,37, peternakan milik Sueb dapat dilihat BEP produksinya pada tahun 2014 yakni sebesar 0,71 sedangkan pada tahun 2015 yakni sebesar 0,66 . Itu artinya peternakan sapi potong di Desa Pucuk, Kecamatan Pucuk, Kabupaten Lamongan mendapatkan keuntungan dan layak untuk dilanjutkan.

Hal ini sesuai dengan kutipan dari Ardhani (2006) dikutip dalam Tri (2015) yaitu BEP dinilai menguntungkan dan layak dilanjutkan jika $\mathrm{BEP}>0$, layak untuk diusahakan, jika $B E P<0$ maka tidak layak untuk diusahakan. Untuk mengetahui rincian yang diperoleh dari nilai total penerimaan yang diterima oleh peternak di Desa Pucuk, Kecamatan Pucuk, Kabupaten Lamongan dapat dilihat pada lampiran.

\section{Return Cost Ratio (R/C)}

$\mathrm{R} / \mathrm{C}$ adalah perbandingan antara penerimaan penjualan dengan biaya-biaya yang dikeluarkan selama proses produksi hingga menghasilkan produk. Usaha ternak sapi potong di Desa Pucuk, Kecamatan Pucuk, Kabupaten Lamongan akan menguntungkan apabila nilai $\mathrm{R} / \mathrm{C}>1$. Semakin besar nilai $\mathrm{R} / \mathrm{C}$ semakin besar pula tingkat keuntungan yang akan diperoleh dari usaha tersebut. Adapun return cost ratio yang diperoleh para peternak di Desa Pucuk, Kecamatan Pucuk, Kabupaten Lamongan dapat dilihat pada tabel 11.

Tabel 11. Return Cost Ratio Usaha Ternak Sapi Potong di Desa Pucuk, Kecamatan Pucuk, Kabupaten Lamongan Pada Tahun 2014-2015.

\begin{tabular}{llrc}
\hline & & \multicolumn{2}{c}{$\mathbf{R} / \mathbf{C}(\%)$} \\
\cline { 3 - 4 } No. & Peternakan & $\begin{array}{c}\text { Tahun } \\
\mathbf{2 0 1 4}\end{array}$ & $\begin{array}{c}\text { Tahun } \\
\mathbf{2 0 1 5}\end{array}$ \\
\hline 1 & Reny & 1,52 & 1,45 \\
& Afidah & 1,38 & 1,79 \\
2 & Chandra & 1,86 & 1,77 \\
3 & Aang & 1,76 & 1,37 \\
4 & Riyanto & 1,39 & 1,50 \\
5 & Suep &
\end{tabular}

Sumber : Data Primer yang Telah Diolah Pada Tahun 2014-2015

Pada tabel.11 dapat diketahui bahwa nilai return cost ratio $(\mathrm{R} / \mathrm{C})>1$ terlihat pada semua peternakan di Desa Pucuk, Kecamatan Pucuk, Kabupaten Lamongan. Peternakan milik Reny Afidah jumlah R/C yang di dapatkan pada tahun 2014 yaitu 1,52 dan pada tahun 2015 yaitu 2,17, pada peternakan Chandra jumlah R/C yang di dapatkan pada tahun 2014 yaitu 1,38 dan pada tahun 2015 yaitu 1,79, pada peternakan Aang jumlah R/C yang di dapatkan pada tahun 2014 yaitu 1,86 dan pada tahun 2015 yaitu 1,77, pada peternakan Riyanto jumlah $\mathrm{R} / \mathrm{C}$ yang di dapatkan pada tahun 2014 yaitu 1,76, dan pada tahun 2015 yaitu 1,37, dan juga pada peternakan Suep jumlah R/C yang di dapatkan pada tahun 2014 yaitu 1,39 dan pada tahun 2015 yaitu 1,50. Itu artinya peternaka sapi potong di Desa Pucuk, Kecamatan Pucuk, Kabupaten Lamongan mendapatkan keuntungan dan layak untuk dilanjutkan.

Hal ini sesuai dengan pendapat Soekartawi (2002) dikutip dalam Tri (2015) yang menyatakan bahwa R/C adalah singkatan dari Return Cost Ratio, atau dikenal sebagai perbandingan (nisbah) antara Penerimaan dan biaya. Kriteria uji: jika $\mathrm{R} / \mathrm{C}>1$, layak untuk diusahakan, jika $\mathrm{R} / \mathrm{C}<1$ maka tidak layak untuk diusahakan. Untuk mengetahui rincian yang diperoleh dari nilai total penerimaan yang diterima oleh peternak di Desa Pucuk, Kecamatan Pucuk, Kabupaten Lamongan dapat dilihat pada lampiran.

\section{Benefit Cost Ratio (B/C)}

$\mathrm{B} / \mathrm{C}$ adalah perbandingan antara tingkat keuntungan yang diperoleh dengan total biaya yang dikeluarkan. Usaha ternak sapi potong di Desa Pucuk, Kecamatan Pucuk, Kabupaten Lamongan akan menguntungkan apabila nilai $\mathrm{B} / \mathrm{C}>1$. Semakin besar nilai $\mathrm{B} / \mathrm{C}$ semakin besar pula manfaat yang akan diperoleh dari usaha tersebut. Adapun benefit cost ratio yang diperoleh para peternakan di Desa Pucuk, Kecamatan Pucuk, Kabupaten Lamongan dapat dilihat pada tabel 12.

Tabel 12. Benefit Cost Ratio Usaha Ternak Sapi Potong di Desa Pucuk, Kecamatan Pucuk, Kabupaten Lamongan Pada Tahun 2014-2015.

\begin{tabular}{clcc}
\hline & & \multicolumn{2}{c}{ B/C (\%) } \\
\cline { 3 - 4 } No. & Peternakan & $\begin{array}{c}\text { Tahun } \\
\mathbf{2 0 1 4}\end{array}$ & $\begin{array}{c}\text { Tahun } \\
\mathbf{2 0 1 5}\end{array}$ \\
\hline 1 & Reny & 0,52 & 1.17 \\
2 & Afidah & 0,38 & 0,79 \\
3 & Aang & 0,86 & 0,77 \\
4 & Riyanto & 0,76 & 0,37
\end{tabular}


5 Suep $\quad 0,39 \quad 0,50$

Sumber : Data Primer yang Telah Diolah Pada Tahun 2014-2015.

Pada tabel.16 dapat diketahui bahwa nilai benefit cost ratio $(\mathrm{B} / \mathrm{C})>1$ terlihat pada peternakan milik Reny Afidah pada tahun 2014 yaitu 0,52 dan pada tahun 2015 yaitu 1,17 , peternakan milik Chandra pada tahun 2014 yaitu 0,38 dan pada tahun 2015 yaitu 0,79 , dan peternakan milik Aang pada tahun 2014 yaitu 0,86 dan pada tahun 2015 yaitu 0,77 , peternakan milik Riyanto pada tahun 2014 yaitu 0,76 dan pada tahun 2015 yaitu 0,37 , dan yang terakhir peternakan milik Suep pada tahun 2014 yaitu 0,39 dan pada tahun 2015 yaitu 0,50 . Jadi bisa dilihat dari uraian diatas hanya peternakan milik Reny Afidah yang mendapatkan keuntungan.

Hal ini sesuai dengan pendapat Gittinger (1986) dikutip dalam Tri (2015), yang menyatakan bahwa Benefit Cost Ratio (BCR) adalah perbandingan antara present value manfaat dengan present value biaya. Dengan demikian benefit cost ratio menunjukkan manfaat yang diperoleh setiap penambahan satu rupiah pengeluaran. BCR akan menggambarkan keuntungan dan layak dilaksanakan jika mempunyai BCR $>1$. Apabila $\mathrm{BCR}=1$, maka usaha tersebut tidak untung dan tidak rugi, sehingga terserah kepada penilai pengambil keputusan dilaksanakan atau tidak. Apabila BCR $<1$ maka usaha tersebut merugikan sehingga lebih baik tidak dilaksanakan. Untuk mengetahui rincian yang diperoleh dari nilai total penerimaan yang diterima oleh peternak.

\section{KESIMPULAN DAN SARAN}

\section{Kesimpulan}

Berdasarkan hasil pembahasan yang telah diperoleh maka dapat disimpulkan bahwa kelayakan usaha pembibitan sapi potong di Desa Pucuk, Kecamatan Pucuk, Kabupaten Lamongan layak dari segi pendapatan, penerimaan maupun finansial (BEP dan R/C Ratio), akan tetapi jika dinilai dari sisi Benefit Cost Ratio (B/C) dari 5 sample peternakan hanya ada 1 peternak yang layak dan menguntungkan yaitu peternakan dengan populasi 40 ekor.

2. Saran

Diharapkan para peternak sapi potong di Desa Pucuk, Kecamatan Pucuk,
Kabupaten Lamongan lebih bersungguhsungguh dalam menjalankan usaha ternak sapi potong ini sehingga pendapatan ataupun keuntungan yang didapatkan semakin besar dan berlipat ganda dari investasi yang ditanamkan.

Sebaiknya para peternak sapi potong beternak lebih dari 10 ekor indukan,dengan umur 2 tahun, dengan bobot $>350 \mathrm{~kg}$ sehingga layak bunting agar jika dinilai dari sisi finansialnya (BEP, R/C Ratio maupun B/C Ratio) usaha pembibitan sapi potong layak dan menguntungkan. Sehingga peternak dapat lebih mensejahtrakan keluarganya dengan memenuhi kebutuhan hidupnya.

\section{DAFTAR PUSTAKA}

Arikunto, Suharsimi. 2006. Prosedur Penelitian. Jakarta. PT. Rineka Cipta.

Diatmojo, dkk. 2012. Analisis Finansial

Usaha Penggemukan Sapi

Peranakan Friesian Holstein (PFH) Jantan di Kecamatan Selo

Kabupaten Boyolali. Universitas Sebelas Maret. Surakarta.

Fadlillah, Nurul. 2013. Skripsi Pengaruh Pembelian Bekalan Sapi Potong Terhadap Pengemukan Sapi. Skripsi. Unisla Press. Lamongan.

Prayogi, Agus. 2014. Skripsi Studi Perbandingan Analisis Usaha Ayam Boiler Dengan Ayam Pejantan Layer. Skripsi. Unisla Press. Lamongan.

Steflyando, Reza, dan Alex. 2014. Analisis Kelayakan Usaha Sapi Potong Dengan Metode Zero Waste Farming Di Kecamatan Parongpong. Bandung. Institut Teknologi Nasional Itenas.

Sugiyono. 2009. Metode Penelitian Administrasi. Bandung : CV. Alfabeta.

Tri, Ariani, Utari. 2015. Analisis Kelayakan Usaha Ternak Sapi Potong Pada Berbagai Skala Kepemilikan Di Desa Samangki Kecamatan Simbang Kabupaten 
Maros. Universitas Hasanuddin. Makassar

Zulfanita, dkk. 2009. Evaluasi Kelayakan Usaha Penggemukan Sapi Potong Gaduhan Di Desa Grantung Kecamatan Bayan Kabupaten Purworejo. UGM. Yogyakarta. 